Of course, social workers are unencumbered by a supervising professional body like the GMC with its considerable legal powers.

United Medical and Dental Schools

Paul Bridges

Guy's Hospital

London SEI

\section{Group therapy with sex offenders}

\section{DeAR Sirs}

I was most impressed with the account of two years of 'A Community Treatment Service for Sex Offenders', by Dr Mendelson et al (Psychiatric Bulletin, October 1988, 12, 416-419).

I thought the readership would like to know of a programme on treating similar patients with group psychotherapy which has been running since 1971 at the Portman Clinic. An account of this clinical research has been written up in "Application of Group Analytical Psychotherapy to those with Sexual Perversions', a chapter that I wrote for a book edited by Terry Lear, entitled Spheres of Group Analysis, and published by Leinster Leader Limited, Nass, Co. Kildare, in 1984. These include selection criteria, composition of these groups, type of leadership and important themes which tend to appear when working with these patients.

Obviously, the technique used by Dr Mendelson and colleagues is a different one, although the early hurdles and the rewards are very much like the ones we encounter in our own work. The description of their treatment confirmed our own findings, when treating similar patients by group psychotherapy at the Portman Clinic. This is an NHS out-patient setting which deals with patients suffering from sexual perversions and who engage in acts of criminality and delinquency.

I would very much welcome a chance to get to know of other professionals in the field who are working in group therapy with similar patients. Those who are interested in exchanging ideas, problems and experiences with other professionals may like to know that the Portman is considering organising a forum for this purpose.

In addition, the Portman Clinic will be offering a series of supervisionary work which will be advertised in this Bulletin later this year.

Portman Clinic

Estela WeLldon London NW3

\section{A hospital drugs review system}

DeAR SiRS

In the long-stay psychiatric hospital regular appraisals of medication are desirable to ensure that in-patients are not receiving drugs inappropriately. At Meanwood Park Hospital, Leeds, with over 300 mentally handicapped patients, a review system has been devised and has been operating for two to three years. Each week a different ward or NHS community outreach residence is taken in turn for a weekly drugs review meeting attended by the psychiatric consultant and registrar, the staff pharmacist, and a nurse with knowledge of the patients. The patients' prescriptions are examined in turn, alterations are agreed, and entries made in the clinical records. Student nurses can attend the meetings. The advantages of the system are:

(a) It ensures that all patients have a periodic review of their medication at least once in every three to six months. Ten to 20 patients can usually be covered in about an hour.

(b) It encourages face-to-face communication between medical, nursing and pharmacy staff.

(c) It helps consistency in prescribing to be achieved.

(d) It enable doctors, nurses and pharmacist to learn from each other and to benefit from the pharmacists' detailed knowledge of drugs.

(e) It brings to light issues which may need to be covered by hospital in-service teaching programmes or an information hand-out.

DOUglas A. SPENCER

Meanwood Park Hospital

Leeds

\section{Private sector psychiatric services}

DEAR SIRS

Your December 1988 issue carried an open letter to the President objecting to the inclusion of a session on private sector psychiatric services in a scientific meeting of the College. I found the views it expressed narrow-minded and self-contradictory.

One of the consequences of nationalising health care delivery systems in the UK has been to stifle innovation and diversity in health care. Part of this has arisen through national and regional constraints placed on service design, especially on the building and redevelopment of hospitals and health centres. This has been compounded through the competition which has arisen between psychiatric and other medical services for scarce resources, a competition in which psychiatric services have tended to do badly. Not surprisingly, since few district or regional health authorities have psychiatrists as members while virtually all have members who reflect the interests of more general medical services.

One key feature of private sector services is their ability to respond to the wishes and needs of their patients. The potential for diversity which this implies makes these services a natural test ground for new approaches to service delivery. Natural 